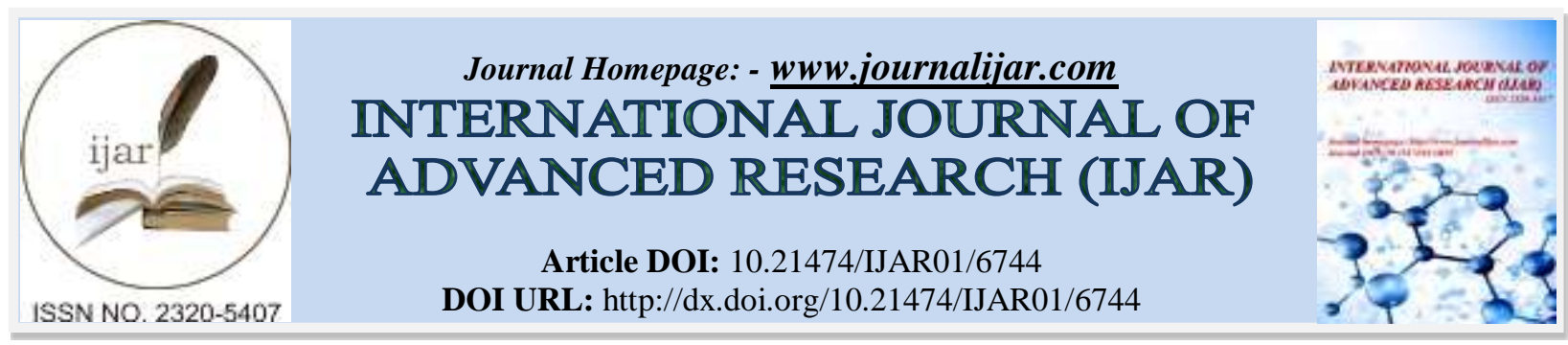

RESEARCH ARTICLE

\title{
A COMPARISON OF HEAT TRANSFER IN FINS WITH DIFFERENT CROSS-SECTIONS.
}

1. B.E. Mechanical.

Chirag J Modi ${ }^{1}$, Darshan M Gohil ${ }^{2}$ and Darshan M Dodiya ${ }^{3}$.

2. B.E. Automobile.

3. CAD-CAM Specialization, Mechanical NITSURAT.

\section{Manuscript Info}

Manuscript History

Received: 14 January 2018

Final Accepted: 16 February 2018

Published: March 2018

Keywords:-

Fins; heat transfer; insulated tips; variation in cross sections; convection; conduction; optimization.

\section{Abstract}

In machine components where heat is generated, it is necessary to remove residual heat from the chamber in order to prevent the failure caused by thermal stresses. Hence, maximum heat must be dissipated by the component into the atmosphere. Fins are help in achieving such heat transfer between the component and atmosphere. This research paper focuses on the geometrical aspects of fins for which the heat transfer that takes place is maximum. It is assumed that the tips of the fins are insulated.

Copy Right, IJAR, 2018,. All rights reserved.

\section{Introduction:-}

Fins are projections of component that help in heat transfer to take place between the control volume and surrounding atmosphere. The heat transfer takes place through conduction (between the walls of component and fins) and convection (heat transfer from fins to atmosphere)[1].

The heat transfer by conduction is given by[2]:

where,

$$
Q=\sqrt{h P k A} \theta_{b} \tanh m L
$$

$Q=$ heat transfer by conduction

$k=$ thermal conductivity of material

$A=$ cross-sectional area

$\theta_{b}=$ temperature difference

$L=$ length of heat travel

$m=\sqrt{\frac{h P}{k A}}$

Thermal analysis was carried out on fins with different cross-sections. The cross-sections taken into consideration were:

- Rectangular

- Square

- Circular

- Triangular

For heat transfer to be maximum with length as the variable, the length of fins with circular cross-section is the highest while that with triangular is minimum among the four cross-sections[3]. But when the length is the same in 
all the fins, the results are not the same. Analysis was carried out considering different parameters for different cross-sections.

\section{A. Parameters}

\section{Rectangular Cross-Section}

In thermal analysis of fin with rectangular cross-section, the dimensions taken were as below:

Width $=0.4 \mathrm{~m}$

Thickness $=0.2 \mathrm{~m}$

Length $=1 \mathrm{~m}$

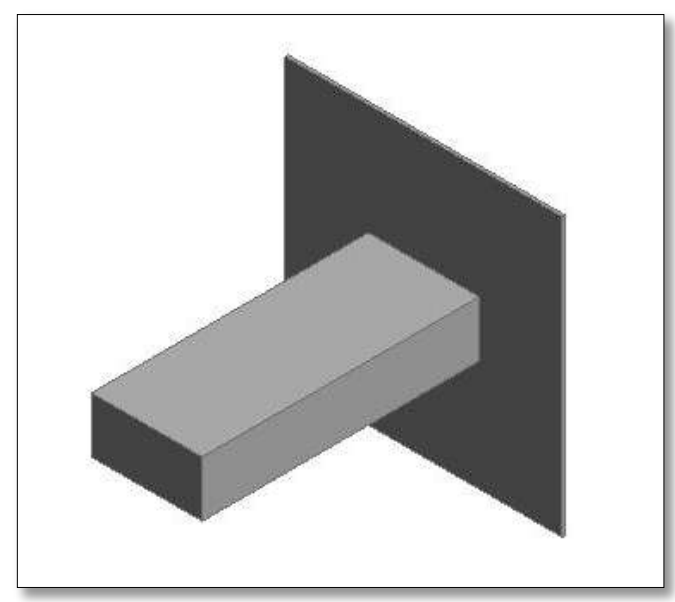

Figure 1:- Fin with rectangular cross-section

\section{Square Cross- Section}

In thermal analysis of fin with square cross-section, the dimensions taken were as below:

Width $=0.2 \mathrm{~m}$

Thickness $=0.2 \mathrm{~m}$

Length $=1 \mathrm{~m}$

\section{Circular Cross-Section}

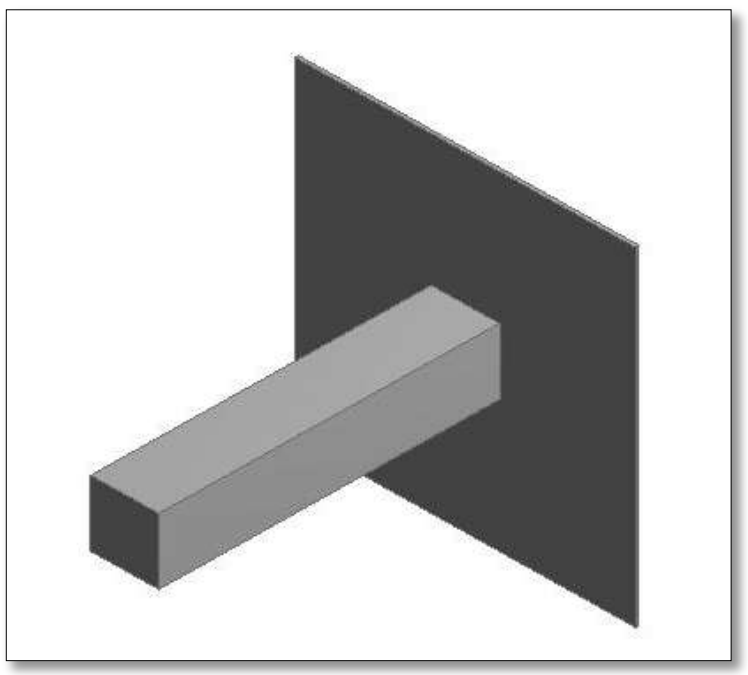

Figure 2:- Fin with rectangular cross-section

In thermal analysis of fin with rectangular cross-section, the dimensions taken were as below:

Diameter $=0.2 \mathrm{~m}$

Length $=1 \mathrm{~m}$ 


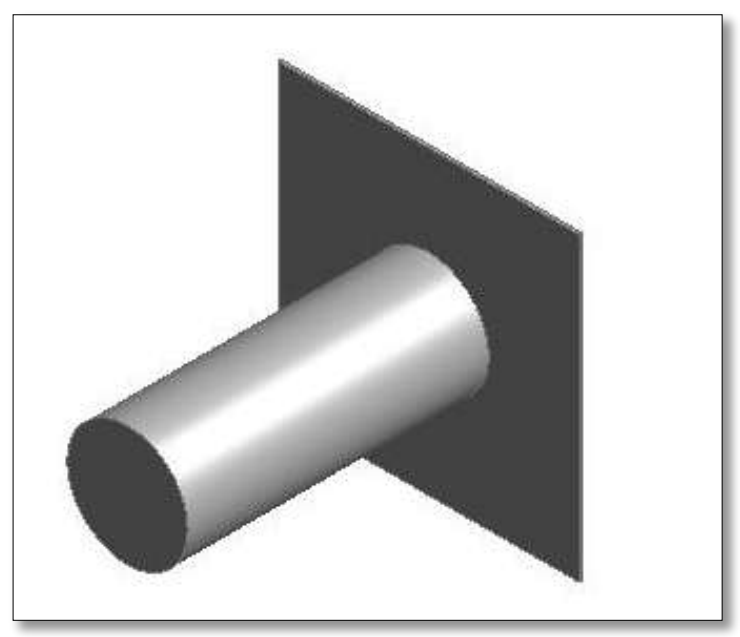

Figure 3:- Fin with circular cross-section

\section{Triangular Cross-Section}

In thermal analysis of fin with triangular cross-section, the dimensions taken were as below:

Length of each side of cross-section $=0.2 \mathrm{~m}$

Length of fin $=1 \mathrm{~m}$

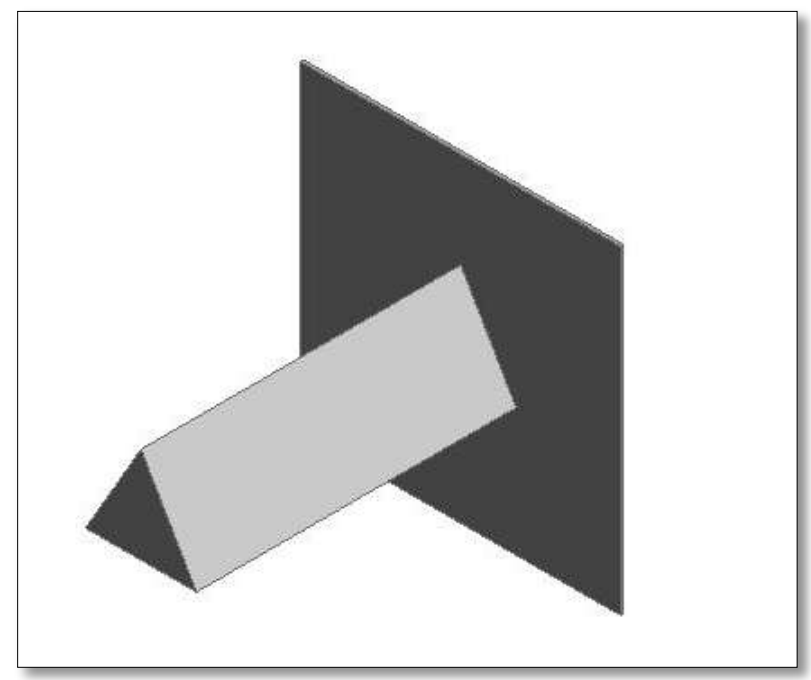

Figure 4:- Fin with triangular cross-section

\section{B. Thermal Analysis on Fins with different cross-sections}

Steady-state thermal analysis of fins withdifferent cross sections was carried out, all having the same length of 1000 $\mathrm{mm}$ and their tips insulated.

Material considered in analysis was "aluminium" whose thermal conductivity is $237.5 \mathrm{~W} / \mathrm{mK}$. Film coefficient is assumed to be $11.875 \mathrm{~W} / \mathrm{m}^{2} \mathrm{~K}$.

The results obtained were noted and plotted in graphical representation: 


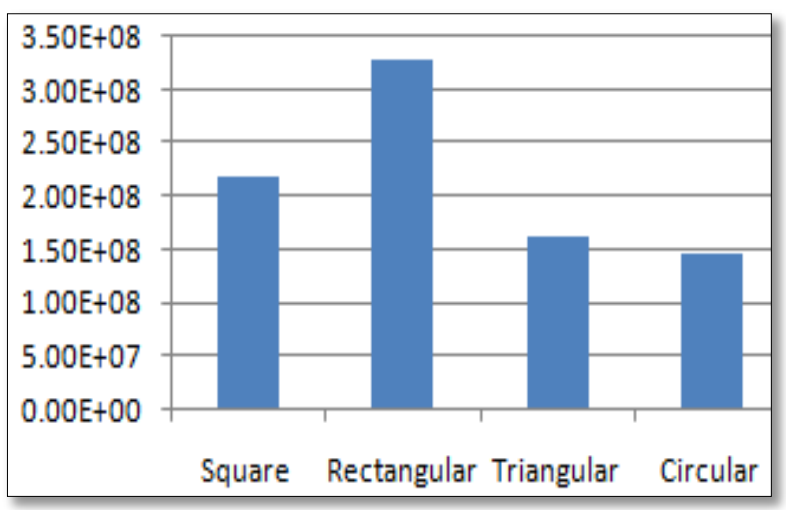

Figure 5:- Graphical representation of Heat Transfer in fins with different cross-sections As shown in the graph, for a particular length, maximum heat transfer took place fin with rectangular cross-section. It was followed by square cross-section, circular and the minimum occurred in fin with triangular cross-section.

\section{Conclusion:-}

From this research paper, it can be concluded that the cross-section of the fins play a huge factor in heat transfer and it becomes an important parameter to choose the proper fin, depending upon the area of interest. For a fixed length, if the heat transfer required should be maximum, rectangular fins are appropriate. However, if the heat transfer taking place should be minimum, circular projections are said to be the better option.

\section{References:-}

1. R.K. RAJPUT Heat and Mass Transfer, $16^{\text {th }}$ Edition, S . CHAND Publication.

2. http://nptel.ac.in/courses/112101001/3

3. C.J. Modi, Optimization of cantilever fin using different types of cross section, IJTRE Vol. 5 issues 5 January 2018. 